\title{
CRISIS FAMILIAR, RESPONSABILIDAD PARENTAL Y ALIMENTOS: REVISANDO LAS CUESTIONES GENERALES EN UN DIVORCIO TRANSNACIONAL (Audiencia Provincial Barcelona - Sentencia de 15/04/2019)
}

\author{
CRISIS OF THE COUPLE, PARENTAL RESPONSABILIT \\ AND MAINTENANCE: REVIEWING CORE MATTERS \\ IN A CROSS-BORDER FAMILY JUDGEMENT \\ (Barcelona Court of Appeal - Decision of 15/04/2019)
}

\author{
Marina Vargas Gómez-Urrutia \\ Profesora Titular de Derecho internacional privado \\ Universidad Nacional de Educación a Distancia (UNED) \\ ORCID ID: 0000-0002-4574-341X
}

Recibido: 16.12.2019 / Aceptado: 10.01.2020

DOI: https://doi.org/10.20318/cdt.2020.5221

\begin{abstract}
Resumen: La interacción entre las normas de competencia judicial internacional y las cuestiones de fondo que resuelven las normas de conflicto en las distintas materias del derecho de familia constituyen un problema específico en los divorcios con elementos transfronterizo. En la SAP Barcelona de 15 de abril de 2019 se pone a prueba el sistema de competencia judicial internacional y de ley aplicable a raíz de una acción principal de divorcio donde, además, se han de establecer medidas de responsabilidad parental y fijar la obligación de alimentos.
\end{abstract}

Palabras clave: competencia judicial internacional, ley aplicable, litigios transfronterizos, divorcio, responsabilidad parental, obligación de alimentos.

Abstract: In family law matters specific issues raises from the interaction between the rules on international jurisdiction and applicable law. The Decision of the Barcelona Court of Appeal rended on April 15, 2019 tests the international jurisdiction system and the issues of applicable law in a cross-border family litigation where a main divorce must be established in addition with parental responsibility measures and maintenance claims.

Keywords: international jurisdiction, applicable law, cross-border UE family law, divorce, parental responsability disputes, maintenance claims.

Sumario: I. Hechos del litigio principal y cuestiones de DIPr presentes en la SAP Barcelona de 15 de abril de 2019. 1. Los hechos del litigio. 2. Sobre la declinatoria internacional y el sistema aplicable a la guarda de la menor. II. Determinación de la residencia habitual en supuestos de crisis matrimoniales internacionales. III. Revisando las líneas generales de la regulación del sistema de competencia judicial internacional y de ley aplicable en los procesos de crisis matrimonial transfronteriza. 1. Pluralidad de instrumentos y pluralidad de foros. 2. Coordinación de instrumentos y adecuación coordinada de los foros y de la ley aplicable. IV. Reflexión conclusiva. 


\section{Hechos del litigio principal y cuestiones de DIPr presentes en la SAP Barcelona de 15 de abril de $2019^{1}$}

\section{Los hechos del litigio}

1. Ante la Audiencia Provincial de Barcelona se plantea un recurso de apelación contra la sentencia de fecha 31 de enero de 2018 dictada por un Juzgado de Primera Instancia e Instrucción en autos de divorcio contencioso. La sentencia decretaba la disolución del matrimonio celebrado entre D. Eladio, de nacionalidad italiana y residente en Barcelona, y $\mathrm{D}^{\mathrm{a}}$ Mónica, binacional colombiana y alemana, residente en Berlín. El matrimonio se había celebrado en Barcelona en el año 2005 constando como último domicilio común dicha ciudad. Son padres de una niña (África) menor de edad que a la fecha de interposición de la demanda vivía temporalmente con su madre en Berlín, con el consentimiento del padre.

2. La sentencia de primera instancia declaraba, a instancias del padre (demandante), además del divorcio, la disolución del régimen económico del matrimonio con adjudicación de la vivienda a $\mathrm{D}$. Eladio y pago a $\mathrm{D}^{\mathrm{a}}$ Mónica de $70.000 €$ en compensación de su parte de gananciales. En relación con las medidas a favor de la menor, la sentencia de instancia, elevando a definitivas las acordadas provisionalmente, estableció que la patria potestad será compartida atribuyendo la guardia y custodia al padre y un régimen de visitas semanal para la madre que "deberá trasladarse a Barcelona para cumplir el mismo". Asimismo, fijó una pensión de alimentos a favor de la menor y a cargo de la madre por importe de $130 €$ mensuales. En relación con los gastos extraordinarios (uniforme, colegio, libros escolares, gastos médicos no cubiertos por la Seguridad Social, deportes, actividades extraescolares, etc.) estableció un reparto proporcional, siendo el $20 \%$ a cargo de la madre y el $80 \%$ a cargo del padre.

3. Contra esta sentencia se alzó la demandada ( $D^{a}$ Mónica) alegando de forma previa vulneración de la tutela judicial efectiva e indefensión e impugnando los pronunciamientos de la resolución recurrida. En particular, reiteraba la falta de competencia judicial internacional del Juzgado de Primera Instancia e Instrucción para conocer de las actuaciones y, para el supuesto de que no se apreciase, solicitaba que se declarase la firmeza de la disolución del vínculo por divorcio y que se ratificase y mantuviese el acuerdo sobre liquidación de la vivienda y régimen económico del matrimonio. Se opuso al resto de los pronunciamientos relativos a las medidas definitivas adoptadas respecto de la menor y solicitó que se autorice el traslado de la menor a Berlín para poder tener consigo a la niña. Subsidiariamente, si no se acordase el traslado de la menor a Berlín, solicitaba que la guarda y custodia fuera otorgada a la madre (quien se trasladaría a la ciudad de Barcelona) y que el régimen de visitas lo fuera a favor del progenitor no custodio (el padre). Y, para el caso de no acordarse esto último, también subsidiariamente, pidió que se establezca un régimen de visitas más amplio. En cuanto a los gastos de la menor, también fueron impugnados por la madre en cuanto a la proporción.

4. Tanto el Ministerio Fiscal como el demandante se opusieron al recurso de apelación, no solo respecto de las peticiones primarias y subsidiarias, sino también en relación con las infracciones procesales denunciadas por la recurrente. En concreto, esta entendía: (A) que en el proceso llevado a cabo en primera instancia se había vulnerado el derecho a la tutela judicial efectiva en su vertiente de "un proceso público sin dilaciones indebidas", al amparo del artículo 24.2 CE. Cabe señalar que en este proceso se tramitó una declinatoria por falta de competencia judicial internacional para la adopción de medidas provisionales previas y que supuso la suspensión el procedimiento principal hasta su resolución. Justamente, es en el análisis de la declinatoria internacional donde la Audiencia Provincial plantea las principales cuestiones de DIPr objeto de esta nota; (B) que había habido lentitud y mal funcionamiento en otros procedimientos paralelos iniciados por la demandada; (C) que se había vulnerado el derecho de la menor a ser oída; (D) que se había infringido el principio de igualdad de la partes; y (E) que no se habían resuelto las pretensiones subsidiarias introducidas durante la vista principal celebrada en primera

${ }^{1}$ SAP B 3980/2019 - ECLI: ES:APB:2019:3980. Fecha: 15/04/2019. Recurso de apelación núm. 472/2018. 
instancia. La Audiencia Provincial estimó parcialmente el recurso de apelación, únicamente por lo que hace al régimen de visitas a favor de la madre (vacaciones de Navidad y Semana Santa), manteniendo el resto de las medidas definitivas adoptadas por la sentencia recaída en primera instancia. En relación con las infracciones procesales denunciadas, todas fueron desestimadas (F.J. Segundo).

\section{Sobre la declinatoria internacional y el sistema aplicable a la guarda de la menor}

5. El FJ Tercero de la sentencia expone los aspectos de Derecho internacional privado presentes en este proceso suscitados, como queda dicho, a raíz de la declinatoria internacional formulada por la demandada impugnando la competencia de los tribunales españoles para conocer de la demanda de divorcio y de las medidas provisionales previas a la misma (resueltas mediante Auto de 16/02/2016 o de 16/09/2016 ${ }^{2}$ ). En esencia, para saber si son competentes los tribunales españoles para conocer de las medidas provisionales solicitadas (responsabilidad parental y alimentos), previas a la demanda de divorcio, ha de dilucidarse la residencia habitual de la menor (España o Alemania) y para la competencia en materia de divorcio, la de los cónyuges. La sentencia declara aplicable: (1) para resolver las cuestiones relativas a la competencia judicial internacional en materia de responsabilidad parental y de divorcio, el Reglamento 2201/2003; y por lo que respecta a la competencia judicial internacional en materia de obligaciones de alimentos, el Reglamento 4/2009 y el Convenio de la Haya de 23 de noviembre de 2007. Nada señala sobre la ley aplicable que, por lo que se verá a continuación, se despeja únicamente respecto de la guarda de la menor aplicando directamente Código civil de Cataluña (en adelante, CCCat).

6. El FJ Cuarto trata la cuestión del interés superior del menor como parámetro de determinación "del sistema de guarda" y se apoya en el artículo 39 de la Constitución española, en los artículos 12 y 15 del Reglamento 2201/2003, en el artículo 3 de la Convención sobre los derechos de niño de 1989 y en el artículo 211.6.1 del Código civil de Cataluña. Afirmado que "corresponde al juez la labor de determinar cuál es el interés del menor en el caso concreto, valorando la situación concurrente teniendo en cuenta las circunstancias fácticas que se dan en cada supuesto".

\section{Determinación de la residencia habitual en supuestos de crisis matrimoniales internacionales}

7. La concreción de la residencia habitual de la menor para la adopción de medidas provisionales en esta sentencia no es cuestión baladí. De acuerdo con el relato de hechos ${ }^{3}$, durante el curso escolar 2014-2015 la menor se habría trasladado a Berlín (Alemania) con su madre, quien estaba realizando una estancia de estudios referente a su tesis doctoral. Consta que la solicitud de medidas provisionales previas a la demanda de divorcio se promovió el 31 de marzo de 2015, por tanto, residiendo la niña en Alemania con su madre. Y que la declaración de competencia de los tribunales españoles para conocer de dichas medidas provisionales previas recayó en Auto de fecha 16 de febrero de 2016. La demanda principal de divorcio se presentó el 25 de febrero de 2016. Consta igualmente que desde septiembre de 2015 la hija común volvió a España y que desde entonces reside en Barcelona con su padre donde está escolarizada. Aunque no se explicita, parece que la madre continuó viviendo en Alemania colaborando en el Departamento de Historia de la Universidad donde realizaba sus estudios de tesis. Otro elemento de (posible) internacionalidad del caso reside en la nacionalidad de los progenitores y de la menor: el padre es italiano y la madre binacional colombiana-alemana. La menor, por consiguiente, no ostenta (en principio) la nacionalidad española.

8. En estas circunstancias, cabe afirmar que el elemento relevante de internacionalidad que justifica la no aplicación de las normas de competencia judicial internacional del Derecho autónomo

\footnotetext{
${ }^{2} \mathrm{El} \mathrm{FJ} 3^{\circ}$ de la sentencia se refiere a este Auto de 2016 con dos fechas diferentes.

${ }^{3}$ F.J. Tercero, apartado $5^{\circ}$ de la sentencia.
} 
español (art. 22 quáter LOPJ) es la distinta residencia habitual de las partes (España y Alemania) cuando se presenta la solicitud de divorcio con establecimiento de medidas provisionales previas. La Audiencia, en su análisis de la residencia habitual, señala que no resulta controvertido que la residencia habitual de la menor al tiempo de la interposición de la demanda de medidas provisionales previas a la demanda de divorcio está en Alemania con su madre, señala que este desplazamiento era temporal (solo un curso académico) y constata que desde septiembre de 2015 la menor reside en Barcelona con su padre, donde está escolarizada. Por lo que hace a la residencia habitual de los cónyuges declara que tenían su último domicilio común en nuestro país. Sobre estos hechos deduce que es clara la residencia en España a los efectos de la atribución de competencia. Ahora bien, ¿es correcta la fundamentación?

9. Como hemos visto en la exposición de los hechos, en el momento en que se iniciaron las actuaciones por el padre, residente en España, la menor residía en Alemania con su madre. De donde cabría interrogarse cómo interpretar esta esta residencia (temporal) a los efectos de fijar la competencia judicial internacional de los tribunales españoles respecto de las medidas provisionales relativas a la responsabilidad parental y a los alimentos. Para dar respuesta a esta interrogante conviene despejar, como primera variable, la noción misma de residencia habitual y, como segunda variable el carácter de los foros del Reglamento 2201/2003 en materia de divorcio y su relación con las medidas sobre responsabilidad parental y las medidas sobre obligación de alimentos.

10. Como es sabido, en las crisis matrimoniales internacionales no solo se dilucida la ruptura, la relajación o la inexistencia del vínculo (divorcio, separación o nulidad) o la disolución del régimen económico del matrimonio, también, en el mismo proceso, se pueden solicitar medidas provisionales previas acerca de la responsabilidad parental y la obligación de alimentos. Pues bien, en estas cuatro materias la residencia habitual juega un papel nuclear al ser criterio de atribución principal de competencia judicial internacional y ser, igualmente, uno de los puntos de conexión de la ley aplicable a cada materia. Cuando la situación fáctica del supuesto es clara, el juez no tendrá problemas para deducir el lugar de la residencia habitual de los cónyuges, del menor o del acreedor de alimentos. Pero numerosos litigios evidencian que, justamente, es la determinación de la residencia habitual el primer elemento de fricción entre las partes. En consecuencia, el tribunal habrá de darse a la tarea de determinar cuál sea esa residencia habitual y cómo funciona el foro de la residencia habitual en los reglamentos concernidos. El resultado no siempre es evidente ni satisfactoria la respuesta, como lo demuestran las diversas cuestiones prejudiciales respecto de las que el Tribunal de Justicia (en adelante, TJUE) ha debido pronunciarse ${ }^{4}$.

11. La inexistencia de una definición única del concepto residencia habitual en los Reglamentos europeos y Convenios de La Haya de Derecho internacional privado de la familia y, en concreto, en aquellos que atienden las materias derivadas de crisis matrimoniales internacionales ${ }^{5}$, ha suscitado

\footnotetext{
${ }^{4}$ Por ejemplo, asuntos: C-523/07, A - ECLI:EU:C:2009:225; C-497/10, Mercredi v. Chaffe -ECLI:EU:C:2010:829; C-376/14, $C$ v. $M$ - ECLI:EU:C:2014:2268; C-111/17, $O L$ v. $P Q$-ECLI:EU:C:2017:436; C-393/18, UD v. XB - ECLI:EU:C:2018:835; C468/18, $R v P$ - ECLI:EU:C:2019:666. El TJUE hace referencia a los factores que han de ser tenidos en cuenta por el juzgador para determinar la residencia habitual del menor. Así: la duración, la regularidad, las condiciones y los motivos de la estancia en el territorio de otro Estado miembro, si la familia se ha mudado o no a dicho Estado, si el menor tiene o no la nacionalidad de ese otro Estado, si en ese otro Estado el menor está escolarizado o no, si conoce o no el idioma, si está integrado y qué tipo de relaciones sociales tiene en ese otro Estado. Ahora bien, no basta con tomar en cuenta estos elementos, conviene explicar su aplicación al caso en cuestión (C-376/14, cit.). Cfr. T. KRUGER, "Chapiter 2. Finding a habitual residence", in: Planning the future of cross border families: a path through coordination. Final Study (I. VIARENGO and F. VILLATA, ed. - JUST/2014/JCOO/AG/CIVI/7729, co-funded by the European Commission under the Civil Justice Programme), Università degli Studi di Milano, 2018, pp. 7489. A nuestro entender, la Audiencia ha perdido una excelente oportunidad de perfilar el concepto de residencia habitual de una menor que temporalmente está en otro Estado miembro por razón de estudios de su madre y despejar claramente que el traslado no era una retención ilícita. Sobre este particular, especialmente interesante el examen de la jurisprudencia del TJUE que realiza B. Campuzano Díaz, en "Una nueva sentencia del TJUE sobre el concepto de residencia habitual en el marco del Reglamento 2201/2003: Sentencia de 17 de octubre de 2018, UD y XB, AS. 393/18 PPU", Cuadernos de Derecho Transnacional (octubre 2019), Vol. 11, No 2, pp. 462-471.

${ }^{5}$ En esta nota nos ocupamos principalmente de los siguientes instrumentos normativos: Reglamento (CE) no $2201 / 2003$ del Consejo, de 27 de noviembre de 2003, relativo a la competencia, el reconocimiento y la ejecución de resoluciones judiciales en
} 
un intenso debate doctrinal y una rica práctica jurisprudencial, tanto de los tribunales nacionales de los Estados miembros como del TJUE. Es un lugar común señalar que las nociones de los reglamentos europeos han de interpretarse de manera autónoma y uniforme y teniendo en cuenta el contexto (interpretación sistemática) y el objetivo de la norma (interpretación teleológica); esto es, desvinculadas de las nociones de los derechos nacionales, con el fin de garantizar la aplicación uniforme de los mismos.

Respecto de la residencia habitual como criterio de aplicación general para la determinación de la competencia judicial internacional y punto de conexión en la norma de conflicto, la doctrina ha analizado las ventajas e inconvenientes ${ }^{7}$. Ahora bien, toda vez que ninguno de los reglamentos europeos en materia de familia define el concepto cabe la duda acerca de su concreción ante el caso concreto. La doctrina ha manifestado que la idea de no cerrar el concepto obedece a la decisión del legislador de que sean los tribunales quienes la determinen, caso por caso, atendiendo al ámbito de aplicación de cada reglamento con unos criterios donde el tipo de litigio y los intereses en presencia ofrezcan las mejores pautas de evaluación. Pero para ello, además de tomar en cuenta las circunstancias fácticas del caso, ha de situarse en el texto de aplicación el precepto concreto de análisis toda vez que los reglamentos concernidos utilizan el concepto en distintos artículos y, eventualmente, con un alcance distinto ${ }^{8}$.

No cabe duda de que la correcta gestión de las normas aplicables y, en particular, los problemas de coordinación de los distintos instrumentos normativos es todo un desafío. No es de extrañar las dificultades de los tribunales nacionales para evitar caer en las inconsistencias ${ }^{9}$ de aquellos cuando han de aplicarlos conjuntamente, como es lo que sucede con los argumentos de la AP de Barcelona en la sentencia de 15 de abril de 2019.

materia matrimonial y de responsabilidad parental, por el que se deroga el Reglamento (CE) n ${ }^{\circ}$ 1347/2000; Reglamento (CE) $n^{\circ} 4 / 2009$ del Consejo, de 18 de diciembre de 2008, relativo a la competencia, la ley aplicable, el reconocimiento y la ejecución de las resoluciones y la cooperación en materia de obligaciones de alimentos. Reglamento (UE) no 1259/2010 del Consejo, de 20 de diciembre de 2010, por el que se establece una cooperación reforzada en el ámbito de la ley aplicable al divorcio y a la separación judicial; Protocolo de La Haya, de 23 de noviembre de 2007, sobre la Ley aplicable a las obligaciones alimenticias; y, Convenio relativo a la competencia, la ley aplicable, el reconocimiento, la ejecución y la cooperación en materia de responsabilidad parental y de medidas de protección de los niños, hecho en La Haya el 19 de octubre de 1996.

${ }^{6}$ Véanse las referencias en A.L. Calvo Caravaca y J. Carrascosa González, Derecho internacional privado, Vol. II, Ed Comares, 2017, p. 545.

${ }^{7}$ J. CARRAscosa GonzÁlez, "Litigación internacional, responsabilidad parental y foro de la residencia habitual del menor en un Estado miembro", en Protección de menores y Derecho internacional privado (A. Cebrián Salvat e Isabel Llorente Martínez, Dirs.), Comares, Granada, 2019, pp. 307-323, esp. pp. 311-312. L.Pérez MArTín, "Determinación y trascendencia de la residencia habitual en las crisis familiares internacionales", en: Crisis matrimoniales internacionales y sus efectos. Derecho español y de la Unión Europea. Estudio normativo y jurisprudencial (M. GuZmÁn ZaPater y M. Herranz Ballesteros, Dirs.), Tirant lo Blanch, Valencia, 2018, pp. 927-963, esp. p. 946.

${ }^{8}$ Por ejemplo, el Reglamento 2201/2003 alude al concepto residencia habitual en los Considerandos 12 (normas de competencia en materia de responsabilidad parental), 17 (restitución del menor en caso de traslado o retención ilícitos) y 18 (resoluciones de no restitución) y en las definiciones del artículo 2 relativas al derecho de custodia (2.9), al derecho de visita (2.10) y al traslado o retención ilícitos (2.11). Asimismo, aluden a la residencia habitual los artículos 6 y 7 del citado Reglamento para establecer las normas de competencia en asuntos relativos al divorcio, a la separación judicial y la nulidad; los artículos 8 a 13 para la competencia en materia de responsabilidad parental; en el artículo 15 sobre la remisión o transferencia de jurisdicción a un órgano menor situado para conocer del asunto; en el artículo 18 sobre la comprobación de la admisibilidad; en el artículo 23 sobre los motivos de denegación del reconocimiento de resoluciones en materia de responsabilidad parental; en el artículo 29 sobre competencia territorial; en el artículo 42 sobre restitución del menor; en el artículo 51 sobre caución o depósito; en el artículo 57 sobre métodos de trabajo de la autoridad central en solicitudes de asistencia e información de los titulares de la responsabilidad parental; en el artículo 61 sobre las relaciones entre el Reglamento con el Convenio de La Haya de 1996; y, finalmente en el artículo 66 sobre la referencia a la residencia habitual en Estado miembros con dos o más ordenamientos jurídicos. Por su parte, en el Reglamento 4/2009, sobre obligaciones de alimentos, la referencia a la residencia habitual está presente en los considerandos 15 (normas de competencia generales), 17 (regla de competencia para la modificación de resoluciones de alimentos a instancia del deudor) y 32 (sobre el criterio de residencia habitual de la persona que tiene derecho a solicitar ayuda de una autoridad central); en el artículo 3 (regla general de competencia); en el artículo 4 (regla de competencia basada en la autonomía de la voluntad); en el artículo 8 (regla de competencia para solicitar por el deudor la modificación de una resolución previamente dictada por otro Estado miembro); en el artículo 11 (sobre la verificación de la admisibilidad); en el 27 (sobre la competencia territorial); en el artículo 32 sobre el recurso contra la solicitud de otorgamiento de ejecución); en el artículo 45 d) sobre justicia gratuita).

9 R. Espinosa Calabuig, "Cross-border Family Issues in the European Union: Multiplicity of Instruments, Inconsistencies and Problems of Coordination", in: Diversity and Integration in Private International Law (V. Ruz ABou-Nigh and M.B Noodt-Taquela, ed), Edimburg University Press, 2019, pp. 65-82, esp. pp. 77 ss. 
12. En la sentencia, el examen de la residencia habitual que justifica la competencia para cada una de las materias sometidas a examen (divorcio, responsabilidad parental y alimentos) no queda bien dibujado. Sí se indican los instrumentos aplicables y los artículos concretos (foros de competencia) pero no los factores que el juzgador tuvo en cuenta para decidir que el matrimonio tuvo su último domicilio en Barcelona y que la menor, al tiempo de la interposición de la demanda, "no había cambiado de residencia". Ambas son cuestiones relevantes para aplicar correctamente los foros de competencia del divorcio, de la responsabilidad parental y de los alimentos. En otras palabras, hubiera sido deseable que el juzgador de instancia y particular la Audiencia Provincial ante cuestión procesal tan relevante como es la declinatoria internacional se hubieran esmerado en delinear el concepto autónomo de la residencia habitual (elementos fácticos concretos y apoyo en la jurisprudencia del TJUE) determinantes para vincular el supuesto a España y declarar así su competencia internacional.

13. Resulta irónico que un concepto tan rico en factores y circunstancias fácticas quede justificado en esta sentencia por referencia a una simple dirección postal en Barcelona de los cónyuges. Bien es cierto que la Audiencia Provincial sí se extiende las circunstancias fácticas de los progenitores cuando analiza el interés superior de la menor y declara que mantiene la decisión del juzgador de instancia respecto de la guarda y custodia a favor del padre. Pero no es menos cierto que estos argumentos hubieran debido servir también para explicar y justificar la vinculación con España de todos los elementos del pleito (en particular, la residencia habitual de la menor como base de la jurisdicción en relación con la responsabilidad parental). Y es que, no hay que olvidar que la menor llevaba viviendo en Berlín con la madre desde hacía más de un año antes de la interposición de la demanda y que también estaba perfectamente escolarizada. ¿Por qué determina el juez que la proximidad del pleito con España es superior a la que pudiera tener con Alemania? Hubiera sido deseable una argumentación basada en la ponderación de todas circunstancias del caso. Por ejemplo, nada se dice del elemento temporal de la residencia de la madre y de la menor en Alemania; no se pondera el grado de integración de la niña en Berlín y sus posibilidades de dominar el lenguaje; tampoco se dice nada sobre su entorno social y familiar en Alemania. Probablemente sea debido a que la Audiencia solo pudo tener en cuenta los informes aportados por el padre que, al parecer, fue la única prueba pericial practicada (aparte de las que sucedieron en el acto de la Vista).

14. Si el juzgador los tuvo en cuenta para ponderar el interés superior del menor para la guarda y custodia, ¿por qué no los utilizó para fundamentar la residencia habitual en la declinatoria internacional? Probablemente, por la inercia de nuestros tribunales de vincular residencia habitual con el domicilio. Como ha hecho notar L. Pérez Martín, "la residencia habitual en Derecho español es un concepto único regulado en el artículo $40 \mathrm{Cc}$ y se sigue considerando que el domicilio de la persona es únicamente uno" ${ }^{\prime 10}$. Abogar por una argumentación judicial más europea (un concepto autónomo de residencia habitual) para la determinación de la competencia judicial internacional cuando se plantea la declinatoria internacional en supuestos de crisis familiares internacionales no solo es deseable sino que mejoraría, qué duda cabe, la calidad técnica y argumentativa de las decisiones de nuestros tribunales.

\section{Revisando las líneas generales de la regulación del sistema de competencia judicial internacio- nal y de ley aplicable en procesos de crisis matrimonial transfronteriza}

15. La ventaja de que sea un único tribunal el que conozca de las diferentes cuestiones que pueden plantearse en un asunto de divorcio internacional (disolución del vínculo, disolución del régimen económico del matrimonio, responsabilidad parental, derechos de custodia, obligación de alimentos) puede quedar comprometida frente al respeto que las particularidades de cada una de estas cuestiones

${ }^{10}$ L. Pérez Martín, "Determinación y trascendencia de la residencia habitual en las crisis familiares internacionales", op.cit., p. 941. 
exige y que lógicamente puede conducir a que sean varios tribunales de Estados diferentes los que, potencialmente, tengan competencia para conocer de estas cuestiones ${ }^{11}$.

16. En el derecho interno español las normas procesales aplicables a los procedimientos de familia en general, y a las crisis matrimoniales en particular, reconducen la pluralidad de problemas a un único tribunal. Esta unidad procesal (art. 773.2 LEC) permitirá y condicionará las medidas que el juez deba adoptar. Por ejemplo, la determinación de los alimentos a satisfacer respecto de los hijos puede incidir en la atribución de la vivienda habitual y esta a su vez en la distribución del patrimonio entre los cónyuges. Las medidas definitivas confirmadas por la sentencia de la Audiencia Provincial de Barcelona objeto de esta nota constituyen un buen ejemplo de lo anterior.

17. Ahora bien, en el ámbito internacional la cuestión se plantea de modo diferente, toda vez que la búsqueda de un tribunal único que se pronuncie sobre los distintos aspectos del litigio exige otro tipo de estrategia procesal y otra manera de razonar, distinta a la seguida en supuestos meramente internos. Además, una vez justificada la competencia judicial internacional debe despejarse el derecho material de aplicación mediante las normas de conflicto que en cada materia rigen la ley aplicable. En las siguientes líneas nos ocuparemos de los diferentes instrumentos normativos relevantes para determinar la competencia judicial internacional en las materias objeto de la sentencia (foros) así como la ley aplicable a dichas materias, poniendo de relieve la pluralidad de instrumentos y de foros así como las dificultades de una adecuada coordinación entre ellos ${ }^{12}$.

\section{Pluralidad de instrumentos y pluralidad de foros}

18. En el apartado anterior habíamos enumerado los instrumentos relevantes que determinan la competencia judicial internacional en materia de divorcio, responsabilidad parental y obligación de alimentos. Como se puede apreciar, es un supuesto típico de crisis matrimonial en el que se aplican dos instrumentos europeos: el Reglamento 2201/2003 y el Reglamento 4/2009. Veamos cómo articulan dichos reglamentos la competencia en cada una de las materias ${ }^{13}$.

19. En relación con los foros del divorcio, el art. 3 del Reglamento traza unos criterios de atribución de competencia (foros) suficientemente próximos o conectados con el tribunal (órgano jurisdiccional) del Estado miembro en cuyo territorio se encuentre la residencia habitual de los cónyuges; o el último lugar de residencia habitual siempre que uno de ellos resida aún ahí; o la residencia habitual del demandado; o en caso de demanda conjunta, la residencia habitual de uno de los cónyuges; o la residencia habitual del demandante si ha residido allí durante al menos un año inmediatamente anterior a la presentación de la demanda; o la residencia habitual del demandante en caso de que haya residido allí al menos seis meses inmediatamente anteriores a la presentación de la demanda y sea nacional el Estado miembro en cuestión.

20. En cuanto a los foros de la responsabilidad parental respecto de menores, señala el artículo 8 del citado Reglamento que son competentes los órganos jurisdiccionales del Estado miembro en que

${ }^{11}$ R. Arenas García, "Principios inspiradores del sistema actual de competencia judicial internacional en materia de persona y familia", en: Persona y familia en el nuevo modelo español de Derecho internacional privado (M. GUZMÁN ZAPATER y C. Esplugues Mota, Dirs.), Tirant lo Blanc, Valencia, 2017, pp. 21-50.

12 ÍDEM, en particular, la reflexión sobre la interacción entre competencia judicial internacional y ley aplicable, p. 45.

${ }^{13}$ Sobre las notas características de los Reglamentos europeos en materia de familia y de sucesiones, S. Alvarez GonzÁLEZ, "Una visión general posible del Derecho internacional privado de familia en la UE", La Ley Digital no 1718/2018, p. 6. Sobre la STJUE C-468/2018, y las normas a aplicar en el derecho de familia europeo, A.L. CAMPo IzQUIERDo, "La determinación de la competencia en los procesos de familia con componente extranjero, Actualidad civi l-Diario La Ley, septiembre, 2019. Y, M. GuzMÁn Peces, "La competencia judicial en materia de nulidad, separación y divorcio; responsabilidad parental y sustracción civil de menores en el Derecho internacional privado español", en: Crisis matrimoniales internacionales y sus efectos, op. cit., pp. 243-277. 
resida habitualmente el menor en el momento en que se presenta el asunto ante el órgano jurisdiccional. Ahora bien, cuando un órgano jurisdiccional está ejerciendo la competencia en virtud de los foros del artículo 3 en una demanda de divorcio (...) estos tribunales tendrán la competencia en las cuestiones relativa la responsabilidad parental vinculadas a dicha demanda cuando al menos uno de los cónyuges ejerza a la responsabilidad parental sobre el menor y cuando la competencia de dichos órganos haya sido aceptada expresamente o de cualquier otra forma inequívoca por los cónyuges $(\ldots)^{14}$.

21. Finalmente, la competencia en materia de obligación de alimentos, no la establece el Reglamento 2201/2003, sino que la indica el R. 4/2009 mediante un sistema algo más complejo pero buscando la coordinación con los otros instrumentos en materia de derecho de familia. Así, por una parte, admite la autonomía de la voluntad (elección de foro, art. 4); y por otra parte, en ausencia de convenio de elección de foro, fija una regla general de competencia basada o en la residencia habitual del demandado o en la del acreedor de los alimentos (apartados a) y b), art. 3). Asimismo, la competencia puede corresponder al órgano jurisdiccional que de acuerdo con su propia ley sea competente para conocer de una acción relativa al estado de una persona o a la responsabilidad parental (apartados c) y d), art. 3). En este sentido, si la demanda de alimentos es accesoria a una acción de divorcio, el juez competente para conocer de la acción principal también tendrá competencia para conocer de la accesoria (alimentos) ${ }^{15}$.

\section{Coordinación de instrumentos y adecuación coordinada de los foros y de la ley aplicable}

22. ¿Cómo razona la Audiencia Provincial para fundamentar la competencia de los tribunales españoles en la sentencia objeto de este comentario? Tras unas consideraciones generales sobre la aplicación preferente del Reglamento 2201/2003 frente a la LOPJ y a sus principios inspiradores en materia de responsabilidad parental concebidas en función del criterio de proximidad y del interés superior del menor, la Audiencia Provincial fundamenta la competencia judicial internacional de los tribunales españoles del siguiente modo (FJ. Tercero):

- Por lo que respecta a las obligaciones alimenticias resulta de aplicación el Reglamento CE/4/2009 (artículo 4.2) y los artículos 10.3, 18 y 20 del Convenio de la Haya de 23 de noviembre de 2007, correspondiendo la competencia de igual forma al domicilio del menor.

- El Reglamento CE 2201/2003 atribuye de igual forma competencia para resolver cuestiones relativas al divorcio de los cónyuges, en virtud de lo que dispone el artículo 3.1 a): "En los asuntos relativos al divorcio (...), la competencia recaerá en los órganos jurisdiccionales del Estado miembro: a) en cuyo territorio se encuentre (enumera los foros...)

- Partiendo de cuanto queda expuesto, resulta necesario declarar la competencia del tribunal español (Juzgado de Primera Instancia $n^{\circ} 6$ de ...) para conocer del procedimiento de divorcio del matrimonio formado por los ahora litigantes en virtud de lo que establece el artículo 3 del Reglamento 2201/2003, al ser el último domicilio común de los cónyuges ahora litigantes y residir alli uno de ellos, correspondiéndole la competencia igualmente par conocer en materia de responsabilidad parental y oblaciones alimenticias, y consiguientemente sobre las cuestiones relativa a la menore que se dilucidan en el presenta procedimiento y ello al ser en beneficio del menor al tratarse del lugar correspondiente al domicilio de la menor".

23. Como valoración de estos argumentos, cabe señalar varios aspectos críticos.

Primero, el orden de aparición de los problemas y de su tratamiento por los instrumentos normativos han de seguir el petitum de la demanda: $1^{\circ}$ divorcio; $2^{\circ}$ responsabilidad parental; y $3^{\circ}$ alimentos. Siendo la acción principal la del divorcio y accesoria la de alimentos, debe empezarse por fijar la com-

\footnotetext{
${ }^{14}$ ÍDEM, op. cit., pp. 257-261.

${ }^{15}$ M. Vargas GómeZ-Urrutia, "Litigios sobre la obligación de alimentos. Normas de competencia y problemas procesales en el Reglamento 4/2009, en Crisis matrimoniales internacionales y sus efectos, op. cit., pp. 317-352.
} 
petencia en materia de divorcio. En concreto, según se ha visto, es el Reglamento 2201/2003 el aplicable y son competentes los tribunales españoles sobre la base de última residencia habitual de los cónyuges si uno de ellos continúa residiendo ahí (como bien lo establece el juzgador por referencia al art. 3).

En segundo lugar, corresponde despejar el foro de la responsabilidad parental para la determinación de las medidas respecto de la menor. El Reglamento 2201/2003 es el aplicable en la materia, si bien los foros son distintos a los del divorcio. ¿De qué modo se coordinan? Como hemos visto, el Reglamento en su artículo 12 coordina el foro de la responsabilidad parental con el foro del divorcio (prorroga de la competencia); de suerte que el órgano jurisdiccional del Estado miembro en que se ejerza la competencia con arreglo al artículo 3 en una demanda de divorcio será competente par conocer de las cuestiones relativas a la responsabilidad parental vinculadas a dicha demanda. En este sentido, es de notar la ausencia de fundamentación jurídica de la Audiencia Provincial respecto de la competencia de los tribunales españoles para conocer y fijar estas medidas.

En tercer lugar, la obligación de alimentos. Señala la sentencia como instrumentos aplicables para la determinación de la competencia de los tribunales españoles el Reglamento 4/2009 (art. 4.2) y el Convenio de La Haya de 23 de noviembre de 2007 sobre Cobro Internacional de Alimentos para los Niños y otros Miembros de la Familia (arts. 10.3, 18 y 20). La referencia al artículo 4.2 del Reglamento $4 / 2009$ no es correcta. Dicho precepto hace referencia al convenio de elección de foro y a las formalidades para su validez. En el caso concreto no se indica que hubiera habido un acuerdo de elección de foro en materia de alimentos. Al contrario, la obligación de alimentos y su cuantía nacen en la sentencia dictada en primera instancia. La competencia pues para conocer de esta materia en esta acción de divorcio la tienen los tribunales españoles en su calidad de tribunales competentes de acuerdo con la ley del foro para conocer de la acción de divorcio, siendo la de alimentos accesoria a aquella (apartado c) art. 3).

24. Más sorprendente resulta la alusión a la aplicación del Convenio de La Haya de 23 de noviembre de 2007. Como es sabido, este Convenio no tiene por finalidad establecer la competencia de los tribunales, sino que estatuye un sistema de cooperación entre autoridades de los Estados parte que permita presentar solicitudes para la obtención de decisiones en materia de alimentos. Ahora bien, este Convenio "no se aplica" entre Estados miembros de la Unión Europea dado que el Reglamento 4/2009 establece su propio sistema de cooperación administrativa entre autoridades centrales y sus funciones (Capítulo VII ${ }^{16}$ ) y porque el Reglamento expresamente establece su prevalencia entre los Estados miembros sobre convenios o acuerdos que se refieran a materias reguladas por el mismo y de los que sean parte los estados miembros (art. 69.2).

25. La ley aplicable. - Una última referencia última, y muy breve, a la determinación de la ley aplicable. En la sentencia se dice que es aplicable el Código Civil de Cataluña para las medidas sobre guarda y custodia de la menor y su forma de ejercicio. ¿Cómo llega la Audiencia a esta conclusión? Ningún fundamento jurídico establece la sentencia para la determinación de la ley aplicable ni al divorcio ni a la responsabilidad parental ni a la obligación de alimentos. Todo el argumentario se centra en la ponderación del interés superior de la menor dando por supuesto que se aplica el Derecho catalán. Pues bien, de igual modo que sucede con las cuestiones relativas a la competencia judicial internacional, la determinación de la ley aplicable requiere conocer los instrumentos aplicables y las normas de conflicto de cada uno de ellos. En este caso, no se precisa una coordinación de instrumentos dado el carácter universal de la ley designada en cada materia.

26. Así, en materia de divorcio es aplicable el Reglamento 1259/2010, de 20 de diciembre ${ }^{17}$. De acuerdo con sus normas de conflicto es aplicable la ley española, pero ¿por qué? ¿puede aplicarse el de-

${ }^{16}$ M. Herranz Ballesteros, "Cooperación entre autoridades administrativas en las crisis matrimoniales internacionales: ámbitos de intervención”, en Crisis matrimoniales internacionales y sus efectos, op. cit., pp. 761-790, esp. p. 779-ss.

${ }_{17}$ Reglamento 1259/2010, de 20 de diciembre, por el que se estable una cooperación reforzada en el ámbito de la ley aplicable al divorcio y a la separación judicial. Alemania y España son Estados participantes en el mismo. Su ámbito de aplicación se refiere a todas aquellas situaciones que impliquen un conflicto de leyes. Su carácter es universal (desplaza las normas de conflicto internas) y sus normas son uniformes (se aplican aunque la ley designada sea de un Estado no participante). 
recho de familia vigente en Cataluña? A la luz del artículo 8, y a falta de elección de ley por la partes, el divorcio se rige por la ley del lugar en que los cónyuges tenían su residencia habitual en el momento de la interposición de la demanda (no es el caso, pues como se ha visto la madre vivía en Berlín y el padre en Barcelona), o en su defecto, en el que los cónyuges hubieran tenido su residencia habitual siempre que no haya finalizado más de un año antes de la interposición de la demanda (podría ser el caso, aunque de los hechos de la sentencia no se deduce claramente la fecha en que la madre se trasladó a Alemania); o en su defecto, de la nacionalidad de ambos cónyuges (no es el caso, el padre era italiano y la madre doble nacional colombiana-alemana); o en su defecto, ante cuyos órganos jurisdiccionales se interponga la demanda (lex fori, que es el caso) ${ }^{18}$.

Declarada aplicable la ley española cabe preguntarse si el Reglamento da solución al problema de aplicación resultante la existencia de Estados con dos o más sistemas plurilegislativos. Es el caso de España $^{19}$. Para ello, ha de estarse a lo dispuesto en el artículo 14 del Reglamento 1259/2010 que proporciona los criterios de solución de los conflictos territoriales. Así, (a) toda referencia a la legislación de tal Estado se entenderá como una referencia a la legislación vigente en la unidad territorial de que se trate; (b) toda referencia al a residencia habitual en tal estado se entenderá como una referencia a la residencia habitual en una unidad territorial. En la especie, la aplicación del Derecho civil catalán al divorcio se justifica por la referencia a la residencia habitual del matrimonio en Barcelona. ¿Y respecto de la responsabilidad parental?

27. En materia de responsabilidad parental, el instrumento normativo que contiene la norma de conflicto es el Convenio de La Haya de 19 de octubre de $1996^{20}$ cuyo artículo 12 establece que cuando las autoridades sean competentes para ejercer la competencia en la materia (ya hemos visto que los son en virtud del Reglamento 2201/2003) estas aplican su propia ley. Y, excepcionalmente, podrían tomar en consideración otra ley de otro Estado con el que la situación tenga un vínculo estrecho. La sentencia de la Audiencia Provincial declara que es aplicable el CCCat. Pero ¿sigue un iter argumental adecuado? En nuestra opinión, no: no solo porque omite la normativa aplicable, sino porque no detecta siquiera que en Derecho internacional privado el orden de aparición de los problemas es secuencial y no basta con justificar la competencia judicial internacional (adecuadamente, a ser posible, en particular cuando se ha planteado una declinatoria internacional) sino que el siguiente paso es determinar la ley aplicable de acuerdo con las normas de conflicto.

Decretada aplicable la ley española en materia de responsabilidad parental, por tener competencia nuestros tribunales para conocer de estas medidas, cabe preguntarse si el Convenio de La Haya de 1996 prevé una solución al problema de la coexistencia en el mismo Estado contratante de más de un sistema jurídico ${ }^{21}$. Como es el caso de España. Los artículos 47 y 48 del Convenio ofrecen la solución interpretativa indicando varios parámetros. Así, para fundamentar la aplicación del derecho catalán, cabría haber hecho referencia al punto 9 del artículo 47 que señala: "cualquier referencia a ley (...) se interpretará como una referencia a la ley (...) de la unidad territorial en la que dicha medida ha sido adoptada". El artículo 48 nos da la pauta sobre cómo determinar la ley aplicable en caso de Estados plurilegislativos: o bien se acude a las normas vigentes en dicho Estado que identifican la unidad territorial cuya ley deberá ser aplicada (en España, art. 16.1 C. civil y referencia a la vecindad civil); o bien, en

18 S. Adroher Biosca, "Derecho aplicable a la resolución de las crisis matrimoniales y a la responsabilidad parental", en Crisis matrimoniales internacional y sus efectos, op. cit., pp. 353-390.

19 J.J. Alvarez Rubio, "Regulación de las crisis matrimoniales y conflictos de leyes internos: una urgente y necesaria reforma", en Crisis matrimoniales internacional y sus efectos, op. cit., pp. 793-902.

${ }^{20}$ Convenio relativo a la competencia, la ley aplicable, el reconocimiento, la ejecución y la cooperación en materia de responsabilidad parental y de medidas de protección de los niños, hecho en La Haya el 19 de octubre de 1996. Su ámbito de aplicación material se refiere ente otras: a) la atribución, ejercicio y privación total o parcial de la responsabilidad parental, así como su delegación; b) el derecho de guarda, incluyendo el derecho relativo al cuidado de la persona del niño y, en particular, el de decidir sobre su lugar de residencia, así como el derecho de visita, incluyendo el derecho de trasladar al niño durante un período limitado de tiempo a un lugar distinto del de su residencia habitual. Su aplicación es de carácter universal (desplaza las normas de conflicto internas) y sus normas son universales (se aplican sin condición de reciprocidad).

${ }^{21}$ J.J. Alvarez Rubio, "Regulación de las crisis matrimoniales y conflictos de leyes internos: una urgente y necesaria reforma", op. cit., p. 824. 
defecto de tales normas, se aplicará la ley de la unidad territorial determinada según las disposiciones del artículo 47.

28. En materia de alimentos, la ley aplicable se rige por lo dispuesto en el Protocolo de La Haya de 23 de noviembre de 2007 por remisión expresa que al mismo realiza el Reglamento 4/2009 en su artículo $15^{22}$. El Protocolo permite la autonomía de la voluntad de las partes para determinar la ley aplicable a la obligación de alimentos, pero no permite tal acuerdo respecto de alimentos a favor menores. De donde, ha de acudirse a la regla general que se contiene en el artículo 3. Así, a la obligación de alimentos se le aplica la ley de la residencia habitual del acreedor, salvo que en el mismo Protocolo se disponga otra cosa. Pues bien, sí existe una regla especial en caso de obligaciones de los padres a favor de los hijos que indica que se aplicará la ley del foro si el acreedor ha acudido a la autoridad competente del Estado de la residencia habitual del deudor. En el caso de la sentencia no ha sido así (recordemos que en el caso sometido a enjuiciamiento las medidas de alimentos tienen carácter accesorio a la demanda principal de divorcio). De donde, volveremos a la regla general (residencia habitual del acreedor) aplicándose a la obligación de alimentos la ley española por ser la de la residencia habitual de la menor (acreedora) ${ }^{23}$.

Determinada la ley española como aplicable, cabe preguntarse si el Protocolo de La Haya de 2007 establece una norma específica para sistemas jurídicos no unificados (como es el caso de España). En efecto, el artículo 16 apartado1 contiene la previsión para este problema de aplicación indicando que cualquier referencia a la ley del Estado se interpretará como una referencia a la ley en vigor en la unidad territorial pertinente. Y, de igual modo que sucede en el Convenio de La Haya de 1996, tratándose de Estados con dos o mas unidades territoriales con su propio sistema jurídico, se aplicarán las normas que en dicho Estado identifican la unidad territorial (en España, art. 16.1 C. civil y referencia a la vecindad civil) o en su defecto la ley de la unidad territorial determinada según las disposiciones del apartado 1 .

\section{Reflexión conclusiva}

29. Se ha dicho, con razón, que el Derecho internacional privado europeo de la familia es "un derecho extravagante" por la multiplicidad de instrumentos y la pluralidad de foros. No resulta extraño así que los operadores jurídicos y los prácticos del derecho (también los teóricos) encuentren dificultades a la hora de realizar una lectura coherente de las normas y de aplicarlas en los distintos sectores y materias de las relaciones familiares internacionales. Por ello, si queremos evitar algunas inconsistencias en la argumentación jurídica de los sectores de problemas y de las materias concernidas, se hace imprescindible tener claras las líneas generales de la regulación de la competencia judicial internacional y de la ley aplicable en casos de divorcios transfronterizos como el presente donde, a la acción principal del divorcio se suman las medidas de responsabilidad parental y la obligación de alimentos.

${ }^{22}$ Protocolo de 23 de noviembre de 2007 sobre la Ley Aplicable a las Obligaciones Alimenticias. Determina la ley aplicable a las obligaciones alimenticias que derivan de una relación de familia, filiación, matrimonio o afinidad, incluyendo las obligaciones alimenticias a favor de un niño con independencia de la situación conyugal de sus padres. Su aplicación es de carácter universal (desplaza las normas de conflicto internas) y sus normas son universales (se aplican sin condición de reciprocidad).

${ }^{23}$ M. Vargas Gómez-Urrutia, "Derecho aplicable a la obligación de alimentos. El Protocolo de La Haya de 2007”, en: Crisis matrimoniales internacional y sus efectos, op. cit., pp. 415-442. 